\title{
Palliative Care in Resource-poor Settings: Inequalities, Challenges, and Opportunities
}

\author{
Ganesh Dangal, ${ }^{1}$ Bishnu Dutta Paudel, ${ }^{2}$ Anjani Kumar Jha ${ }^{1}$ \\ ${ }^{1}$ Nepal Health Research Council (NHRC), Kathmandu Nepal, ${ }^{2}$ National Academy of Medical Sciences (NAMS), \\ Bir Hospital, Kathmandu Nepal.
}

Palliative care is, according to WHO, "an approach that improves the quality of life of patients and their families facing the problems associated with life-threatening illness, through the prevention and relief of suffering". The need for palliative care is increasing throughout the world as it is well known that palliative care improves quality of life for seriously ill patients and their families but the palliative care needs of all patients are being addressed inadequately in resource-poor settings. Although developed western world has a rapidly growing system in place for palliative care services, clinical, research and educational programs; it is negligible in the developing countries. ${ }^{2}$

The great majority of world's population is in developing countries and these countries are progressively faced with an ageing population, and subsequent increase in chronic illness and higher prevalence of cancers needing more palliative care. Insufficient access to care for cancer, AIDS and terminal illnesses make palliative care the only feasible response in many situations. The global burden of cancer and other non-communicable diseases is growing; however the funds and resources for effective treatment of pain and terminal illness are scarce in poor countries. Lacking access to the opioids that are easily available in the developed world to treat the intractable pain of terminal illnesses/cancers is crucial in developing world. Majority of world's population are unable to gain access to high-quality cancer care. Even though opioids like morphine for treatment of severe pain are easy to produce and cheap, morphine is not available in more than 150 countries. ${ }^{3}$ Developing countries like Nepal have other competing priorities and palliative care has received little attention. Although there has been some progress in development of palliative care in Nepal, this is limited to urban areas and inadequate. ${ }^{4,5}$

Palliative care can be provided with limited resources with minimal infrastructure support as shown exem- plarily in Kerala, India. In India, a million people with cancer and other incurable and disabling diseases need opioids for pain relief. Only about $0.4 \%$ of the population in need have access to them. After long and sustained efforts by palliative care enthusiasts, India has simplified narcotic regulations following lobbying educational interventions and awareness among all stakeholders, but opioid availability has improved only in a minority of the Indian states. ${ }^{6}$

In our country, physicians focus more on opiates' side effects and opioid addiction, not their potential benefits, and pain control and palliative care are taught only in some medical schools. Other major barriers to access to opioids are regulations and problems related to attitude and knowledge regarding opioids among health professionals, policy makers and the public. Developing world, where majority of cancer patients come at the late stage, generally lacks basic palliative care services and the essential medicines necessary to provide these services. Due to increase in cancer prevalence and elderly population, thus there is now an increase in the number of patients needing palliative care. Palliative care has been developing gradually for a decade or so in these countries and many organizations contributed for this growth in developing countries like Nepal.Opioids use and availability is also limited to cities only and is under-prescribed by physicians due to fear of misuse, lack of awareness, and others. Nepal government has recently passed National Strategy of Palliative Care. Barriers to palliative care are inadequate prescribing by physicians and limited support by the government in pain management and palliative care. In many developing countries, even if a physician is licensed to prescribe morphine, there are substantial impediments to administering the drug. ${ }^{5,7}$

Health care providers in resource-poor settings struggle to provide palliative care with limited resources, and efforts are underway to address the specific need for 
palliative care by establishing an association of palliative care workers and some local volunteer organizations and international organisations supporting palliative care works. The governments seem to be receptive and positive regarding support and funding of palliative care although it has other competing priorities. There is also a significant lack of trained professionals and shortage of pain and palliative care specialists. Current palliative care institutions are limited in number and centred in cities with insignificant home hospice program; leaving behind the patients from rural areas in suffering. The providers have also been involved in palliative care researches but this area is still in infancy due to obvious reasons of lack of resources. ${ }^{5,7} \mathrm{WHO}$ recommendations that recognize the need for policy, drug availability, and education, and funds to centers for palliative care; should be adopted by all. ${ }^{8}$ However, simplification of narcotic regulation by itself will not improve opioid availability to the needy unless it is coupled with advocacy, awareness among public education of the health care professionals in pain management and palliative care, and its integration into the health system.

The implementation of palliative care is a global health challenge, and millions in low and middle-income countries, experience unnecessary sufferings and pain without access to morphine and opioids. Through advocacy, policy and strong commitment to compassion, enthusiast healthcare workers can provide much needed palliative care integrated into a healthcare system in resource poor settings, however the support and sustained efforts from the local governments and international stakeholders are very crucial and critical. There have been visible and remarkable efforts in advancing palliative care and an increase in the access to palliative care in the resource-poor countries. However, the progress has been slow but encouraging. The development of palliative care services has steadily increased, but the availability of morphine has remained inconsistent and inadequate. Palliative care, not limited to pain control, should be provided in the community to the extent possible. It needs combined efforts from all to establish state of art palliative care system in the countries by making national policy and guidelines, by incorporating it in the medical curricula and by raising awareness among the providers, patients, families and public.

\section{REFERENCES}

1. WHO. WHO Definition of Palliative Care [Internet]. WHO. [cited 2017 Sep 19]. [Full Text]

2. Clemens KE, Kumar S, Bruera E, Klaschik E, Jaspers B, De Lima L. Palliative care in developing countries: what are the important issues?. Palliat Med. 2007 Apr;21(3):173-5. [PubMed]

3. Statement of Professor Sevil Atasoy, President of the International Narcotics Control Board, to the United Nations Economic and Social Council [Internet]. [cited 2009 Jul 30]. [Full Text]

4. Brown S, Black F, Vaidya P, Shrestha S, Ennals D, LeBaron VT. Palliative Care Development:The Nepal Model. J Pain Symptom Manage. 2007;33:573-77.[PubMed]

5. Paudel BD, Dangal G, Munday D. Overview of Palliative Care. NJOG. 2014;9(2):3-10. DOI: http://dx.doi. org/10.3126/njog.v9i2.11724[Full Text]

6. Rajagopal MR, Joranson DE. India: opioid availability: an update. J Pain Symptom Manage. 2007;33:615-622. [PubMed]

7. IAHPC Traveling Scholar's Report - International Association for Hospice \& Palliative Care [Internet]. [cited 2017 Sep 19]. [Full Text]

8. World Health Organization. Achieving balance in national opioids control policy: Guidelines for assessment. Geneva: World Health Organization; 2000.[Full Text] 